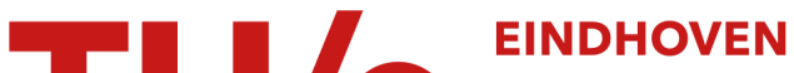 \\ UNIVERSITY OF \\ TECHNOLOGY
}

\section{Controlling ultrafast transport in magnetic heterostructures}

Citation for published version (APA):

Schellekens, A. J., \& Koopmans, B. (2015). Controlling ultrafast transport in magnetic heterostructures. Springer Proceedings in Physics, 159, 232-234. https://doi.org/10.1007/978-3-319-07743-7_72

\section{Document license:}

TAVERNE

DOI:

10.1007/978-3-319-07743-7_72

Document status and date:

Published: 01/01/2015

\section{Document Version:}

Publisher's PDF, also known as Version of Record (includes final page, issue and volume numbers)

\section{Please check the document version of this publication:}

- A submitted manuscript is the version of the article upon submission and before peer-review. There can be important differences between the submitted version and the official published version of record. People interested in the research are advised to contact the author for the final version of the publication, or visit the $\mathrm{DOI}$ to the publisher's website.

- The final author version and the galley proof are versions of the publication after peer review.

- The final published version features the final layout of the paper including the volume, issue and page numbers.

Link to publication

\section{General rights}

Copyright and moral rights for the publications made accessible in the public portal are retained by the authors and/or other copyright owners and it is a condition of accessing publications that users recognise and abide by the legal requirements associated with these rights.

- Users may download and print one copy of any publication from the public portal for the purpose of private study or research.

- You may not further distribute the material or use it for any profit-making activity or commercial gain

- You may freely distribute the URL identifying the publication in the public portal.

If the publication is distributed under the terms of Article 25fa of the Dutch Copyright Act, indicated by the "Taverne" license above, please follow below link for the End User Agreement:

www.tue.nl/taverne

Take down policy

If you believe that this document breaches copyright please contact us at:

openaccess@tue.nl

providing details and we will investigate your claim. 


\title{
Controlling ultrafast transport in magnetic heterostructures
}

\author{
A.J. Schellekens and B. Koopmans \\ Department of Applied Physics, Center for NanoMaterials (cNM), Eindhoven University of \\ Technology, P.O. Box 513, 5600 MB Eindhoven, The Netherlands \\ a.j.schellekens@tue.nl
}

\begin{abstract}
We report on recent experiments addressing the interplay between magnetic ordering and spin/heat transport after femtosecond pulsed laser excitation. First, we demonstrate ultrafast magnetic control of heat flow through a metallic spin valve. Second, we show an experimental indication that superdiffusive spin currents can exert a spin-transfer torque on unprecedented timescales.
\end{abstract}

\section{Introduction}

The field of ultrafast magnetism has come a long way since the first observation of sub-picosecond demagnetization of $\mathrm{Ni}$ after femtosecond (fs) laser heating [1]. Where first it was only possible to create disorder in ferromagnetic materials, new phenomena like reversal of ferrimagnetic alloys $[2,3]$ and the generation of large non-equilibrium spin currents [4] have shown to be possible by pulsed laser excitation. Further exploring magnetism and spintronics on the ultimate timescale is of utmost importance to both fundamental understanding of these processes as to improve the speed and efficiency of future spintronic devices.

Here we present measurements on two phenomena in the field of spintronics, being giant thermal magnetoresistance (GMTR) and spin-transfer torque (STT), which yet are unexplored at (sub-)ps timescales after pulsed laser excitation. First, we show that the demagnetization of a ferromagnetic thin film can be altered by a neighboring spin-valve, providing magnetic control of heat transport on unprecedented timescales. Second, we discuss a pilot study of the control of the orientation of a non-collinear magnetic bilayer by ultrafast STT.

\section{Ultrafast Giant thermal magnetoresistance}

In metals thermal conductivity is governed by the free electrons, implying that thermal and electrical conductivity are related. In a magnetic bilayer separated by 
a conductive spacer layer the electrical conductivity is related to the mutual orientation of the magnetization in the magnetic layers, which is called giant magnetoresistance (GMR). The related effect, i.e. that the thermal conductivity of such a bilayer also depends on the mutual orientation, has already been demonstrated [5]. Here, we investigate this so called GMTR on ultrafast timescales after fs laser excitation, paving the way for ultrafast magnetic control of heat flow.
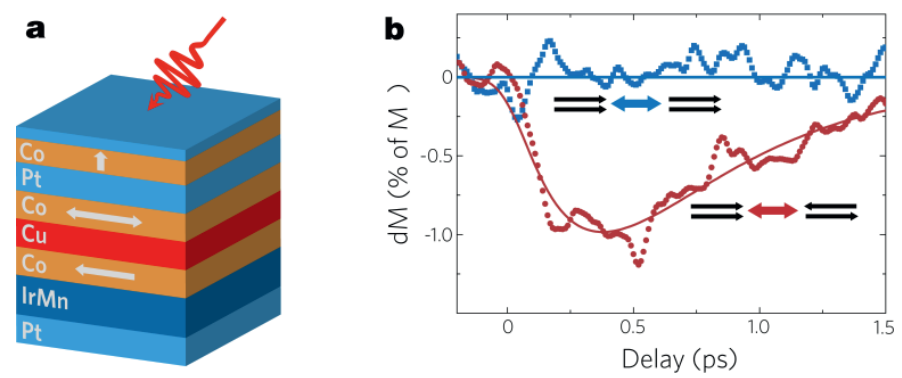

Fig. 1. (a) Sample grown for investigating ultrafast GMTR. (b) Change in demagnetization of the perpendicular $\mathrm{Pt} / \mathrm{Co} / \mathrm{Pt}$ layer by changing the orientation of the spin valve by an in-plane magnetic field, including a reference measurements where the applied field was marginally smaller than the switching field.

The idea behind the experiments is depicted in Fig. 1(a). An intense fs laser pulse heats a perpendicularly magnetized $\mathrm{Pt} / \mathrm{Co} / \mathrm{Pt}$ layer. The amount of heat transport is controlled by the $\mathrm{Co} / \mathrm{Cu} / \mathrm{Co} \mathrm{GMR}$ stack below the top layer. In Fig. 1(b) the change in demagnetization between the parallel and anti-parallel configuration $\mathrm{dM}$ is plotted as a function of delay time as measured by time-resolved MOKE. When the in-plane field is too small to switch the GMR stack, no signal is observed. However, when the applied field exceeds a critical value, a clear change of about $1 \%$ in the demagnetization efficiency is measured. A negative value of $\mathrm{dM}$ means that the demagnetization is smaller in the parallel alignment. This is expected, since a parallel orientation means a large electrical and thermal conductivity, leading to faster transport of heat away from the top layer, finally resulting in a smaller demagnetization.

\section{Ultrafast spin-transfer torque}

Although the presence of ultrafast spin currents after fs laser pulse excitation is well established [6], these currents have not yet been used to actually control the orientation of magnetic layers on ultrafast timescales. Here, we show preliminary experimental evidence that ultrafast spin currents can induce a torque on a magnetic layer on unprecedented timescales. 

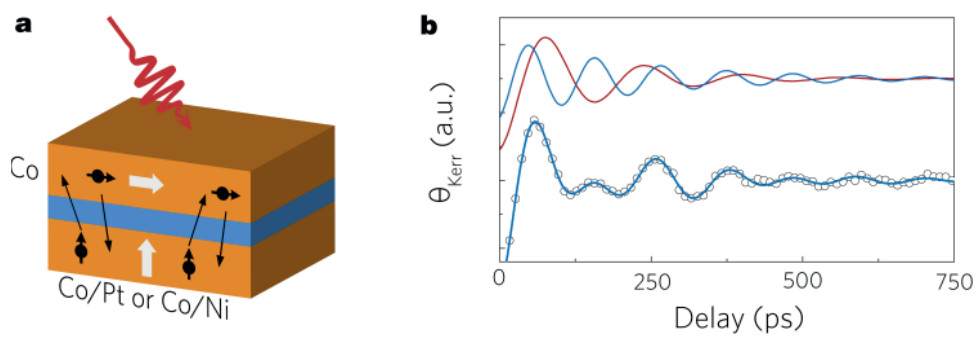

Fig. 2. (a) Sample grown to investigate ultrafast STT. (b) Time resolved Kerr measurements, revealing a precession of both the top and bottom magnetic layer. The lines through the data are fits with a double exponentially decaying sine, and the separate lines are the fitted individual precessions plotted with a slight offset for clarity.

In Fig. 2(a) the sample to investigate STT after pulsed laser excitation is depicted. Two non-collinear magnetic layers are separated by a conductive spacer layer, allowing for exchange of angular momentum. Due to the non-collinear alignment the transferred spins exert a torque on the magnetization, bringing the system out of equilibrium. After the ultrafast spin currents, the magnetization will precess back to equilibrium.

In Fig. 2(a) an example of the precessions induced by ultrafast STT is depicted. Two oscillations, corresponding to the top and bottom layer, can be clearly distinguished. The properties of these oscillations as a function of applied field, field angle, and spacer layer thickness suggest that superdiffusive spin currents from the bottom to top layer are at the origin of the precession of the top layer. The STT caused by superdiffusive spin currents can provide a method to switch the magnetization of magnetic bits on unprecedented timescales.

\section{References}

[1] E. Beaurepaire, J.C. Merle, A. Daunois, J.-Y. Bigot, "Ultra-fast spin dynamics in ferromagnetic Nickel" Phys. Rev. Lett. 76, 4250(1996).

[2] I. Radu et al., "Transient ferromagnetic-like state mediating ultrafast reversal of antiferromagnetically coupled spins" Nature 472, 205-208 (2011).

[3] A.J. Schellekens and B. Koopmans, "Microscopic model for ultrafast magnetization dynamics of multisublattice magnets" Phys. Rev. B 87, 020407(R) (2013).

[4] M. Battiato, K. Carva, P.M. Oppeneer, "Superdiffusive Spin Transport as a Mechanism of Ultrafast Demagnetization" Phys. Rev. Lett. 105, 027203 (2010).

[5] D. Daniela, J.F. Gregg, S.M. Thompson, J.M.D. Coey, A. Fagan, K. Ounadjela, C. Fermon, G. Saux, "Thermal conductivity of a giant magnetoresistive mechanical alloy" J. Magn. Magn. Mater. 140, 493 (1995).

[6] G. Malinowski et al., "Control of speed and efficiency of ultrafast demagnetization by direct transfer of spin angular momentum" Nature Physics 4, 855-858 (2008). 